\title{
The Effect of PIPS on Three Different Types of Dentin: A Surface Observational Study
}

\author{
${ }^{1}$ Vivek Hegde, ${ }^{2}$ Amulya Vangala, ${ }^{3}$ Paresh Jain, ${ }^{4} S$ Srilatha, ${ }^{5}$ Vignesh Dixit
}

\begin{abstract}
Aim: To study the effect of $17 \%$ EDTA with PIPS on dentinal surfaces of pediatric, adolescent and geriatric teeth using scanning electron microscope (SEM).

Background data: The debriding ability of an Er:YAG laser system equipped with a new tapered and stripped tip of 400 micron diameter and auxiliary irrigating solutions after mechanical preparation.
\end{abstract}

Materials and methods: For each group, 20 single rooted human mandibular premolars were selected. The groups were categorized as group 1 pediatric, group 2 adolescent and group 3 geriatric. These groups were further divided as subgroup $A$ (control) - saline and subgroup B-EDTA and PIPS. Access opening was done for all the samples and respective irrigation protocol was followed. The samples were then sectioned and observed under SEM.

Results: The observational study shows that the efficacy of smear layer removal was better in the pediatrics group followed by adolescent and geriatric groups.

Conclusion: The PIPS technique resulted in effective debriding and decontamination of the root canal system in all the three types of dentin.

Keywords: PIPS, EDTA, Er:YAG, SEM.

How to cite this article: Hegde V, Vangala A, Jain $P$, Srilatha $S$, Dixit V. The Effect of PIPS on Three Different Types of Dentin: A Surface Observational Study. World J Dent 2015;6(1):5-9.

Source of support: Nil

Conflict of interest: None

\section{INTRODUCTION}

Debridement of the root canal by instrumentation and irrigation is considered the most important single factor in the prevention and treatment of endodontic diseases. ${ }^{1}$ The traditional technique used mechanical instrument

\footnotetext{
${ }^{1}$ Professor and Head, ${ }^{2}$ Postgraduate Student

${ }^{3}$ Private Practitioner, ${ }^{4}$ Reader, ${ }^{5}$ Professor

1,2,4,5Department of Conservative Dentistry and Endodontics MA Rangoonwala College of Dental Sciences and Research Centre, Pune, Maharashtra, India

${ }^{3}$ Department of Conservative Dentistry and Endodontics, Pune Maharashtra, India

Corresponding Author: Amulya Vangala, 2390-B, KB Hidayatullah Road, Azam Campus, Camp, Pune-411001, Maharashtra India, Phone: +91 8411929233, Fax: 020 26430962, e-mail: amulyavangala@gmail.com
}

ultrasonics along with chemical attempt to shape, clean and decontaminate the root canal system. These techniques still could not remove all the debris and infective microorganisms. Therefore, appropriate to search for new materials, techniques and technologies that can improve the cleaning and decontamination. ${ }^{2}$

Among the newer technologies, the laser has been widely used in endodontics since the early 1990s. ${ }^{3}$ Studies reported that near infrared lasers are highly efficient in disinfecting the root canal surfaces and dentinal walls (up to 750 microns with the $810 \mathrm{~nm}$ diode laser and up to $1 \mathrm{~mm}$ with the $1064 \mathrm{~nm} \mathrm{Nd:YAG} \mathrm{laser).} \mathrm{On} \mathrm{the} \mathrm{other}$ hand, these wavelengths did not show effective results in debriding and cleansing the root canal surfaces and also caused characteristic morphological alterations of the dentinal wall. The smear layer was only partially removed and the dentinal tubules primarily closed as a result of the melting of inorganic dentinal structures. ${ }^{4}$

Recent studies have reported how the use of an Er:YAG laser, equipped with the newly designed radial and stripped tip, used along with 17\% EDTA solution, using a very low pulse duration (50 microseconds) and low energy $(20 \mathrm{~mJ})$ resulted in effective debris and smear layer removal with minimal or no thermal damage to the organic dentinal structure through a photoacoustic technique called photon induced photoacoustic streaming or 'PIPS ${ }^{\mathrm{TM}^{\prime}}$. ${ }^{5,6}$ Based on the available literature, this study was formulated to evaluate the efficiency of $17 \%$ EDTA with PIPS on the dentinal surface of three different age groups.

\section{MATERIALS AND METHODS}

A total of sixty freshly extracted, single rooted human teeth were selected for the study. The teeth were selected based on the age groups and categorized as: Group 1 $(n=20)$ - pediatric (primary teeth), Group $2(n=20)$ adolescent (teeth from patients aged 15-21 years), group 3 ( $n=20$ )-geriatric (teeth from patients aged above 60 years). Access opening was done for all the specimens. The patency was established using a \#10 k-file and it was confirmed by the appearance of the file at the root apex. Working length was determined, root canals were prepared using the hand Protaper files up to F3. Canals were irrigated with $2 \mathrm{ml}$ of saline between file sizes. 
These groups are further divided based on the irrigating systems as follows:

- Subgroup A (control group) was hand activated for 40 seconds in saline solution-wetted canal.

- Subgroup B was laser-irradiated using PIPS for 40 seconds in 17\% EDTA-wetted canal. Laser settings were $20 \mathrm{~Hz}, 40 \mathrm{~mJ}$, with air/water spray off.

During laser irradiation, the root canals were continuously irrigated with $2 \mathrm{ml}$ of $17 \%$ EDTA to maintain hydration and fluid levels using a 25-gauge needle in a sterile syringe. The laser tip was positioned in the coronal aspect of the tooth. The prepared samples were then sectioned longitudinally and examined with a scanning electron microscope (SEM).

\section{OBSERVATION AND RESULTS}

The images were analyzed by three observers evaluated the amount of remaining smear layer. SEM images at magnification 4000× were used for this quantitative assessment (Figs 1 to 6). A mean smear layer score was calculated for each specimen, according to the scoring system proposed by Torabinejad et al.
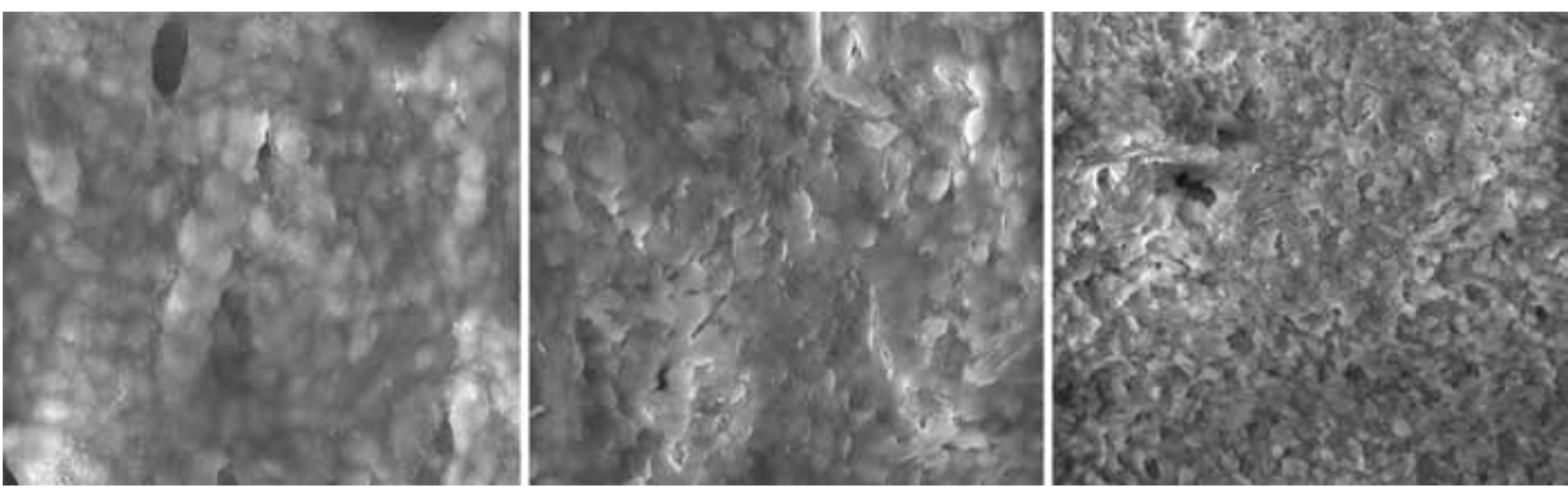

Fig. 1: Group 1A: saline (control group); pediatric teeth: SEM images of coronal third-heavy smear layer, score 2 middle third—heavy smear layer, score 2 apical third—heavy smear layer, score 2
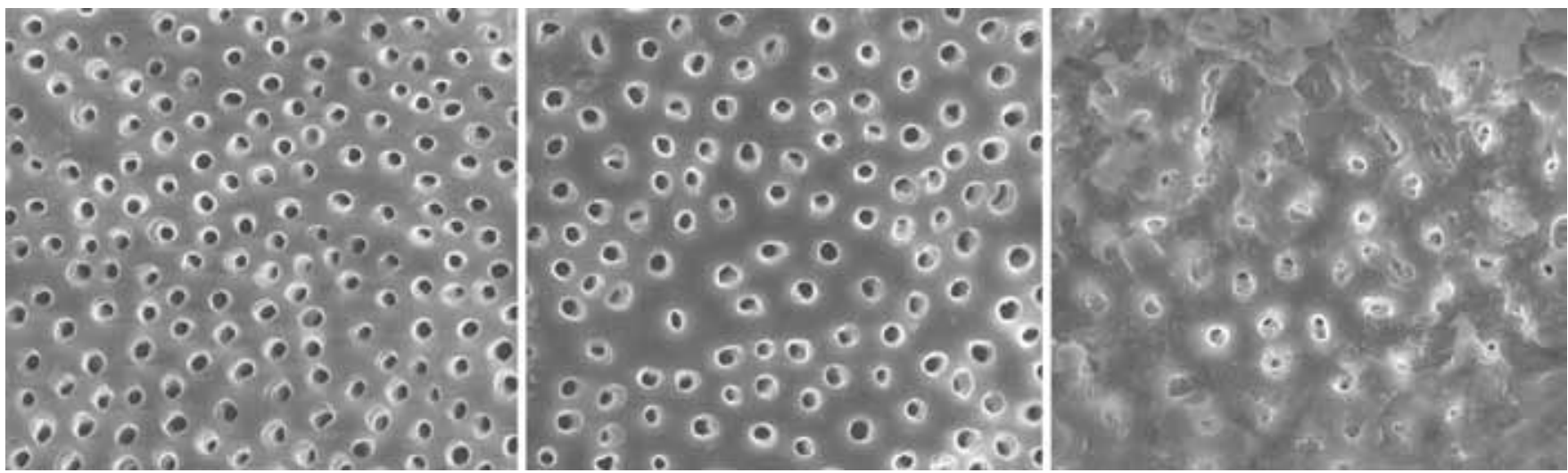

Fig. 2: Group 1B: PIPS group; pediatric teeth: SEM images of coronal third-no smear layer, score 0 middle third-no smear layer, score 0 apical third—no smear layer, score 0
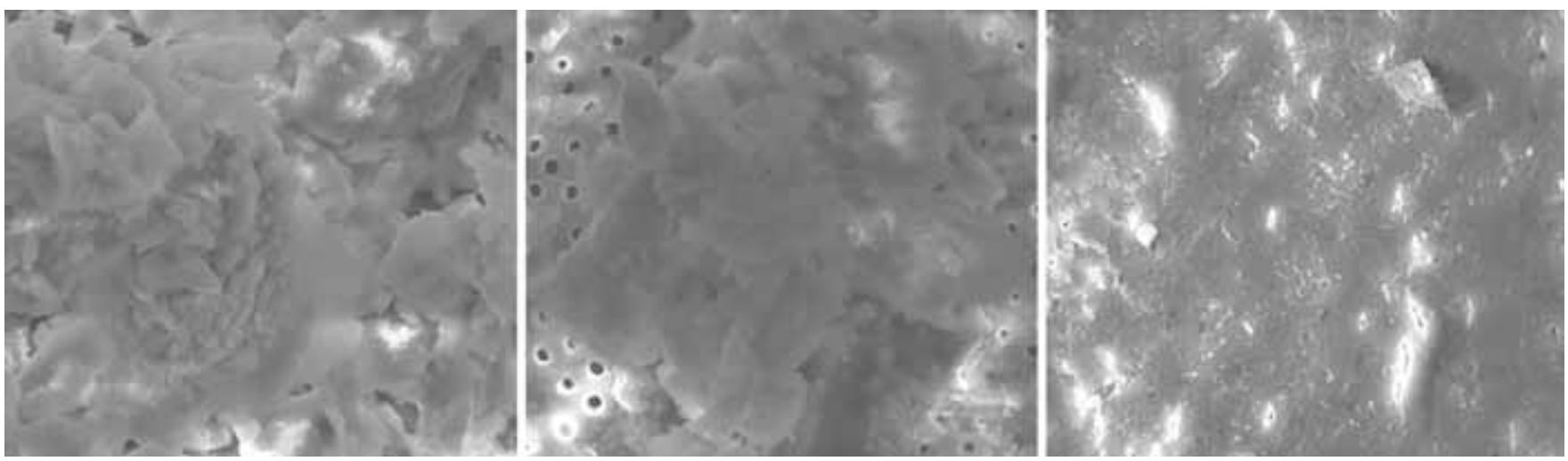

Fig. 3: Group 2A: saline (control group); adolescent teeth: SEM images of coronal third-heavy smear layer score 2 middle third-moderate smear layer, score 2 apical third—moderate smear layer, score 2 

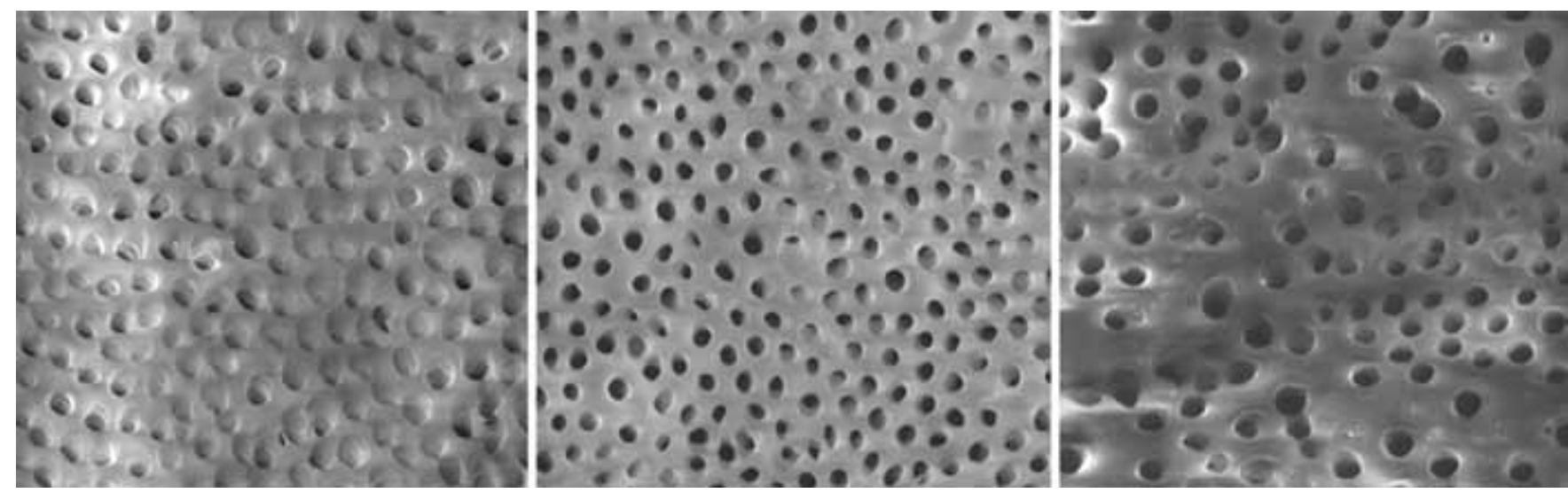

Fig. 4: Group 2B: PIPS group; adolescent teeth: SEM images of coronal third-no smear layer, score 0 middle third-moderate smear layer, score 0 apical third-no smear layer, score 0
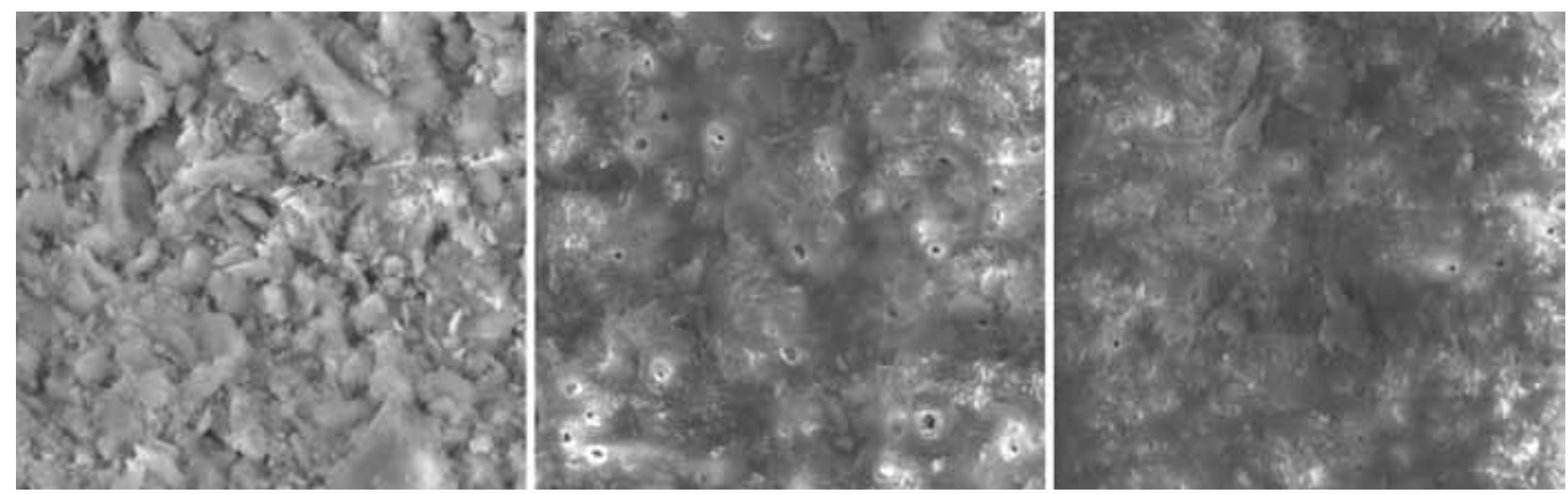

Fig. 5: Group 3A: saline (control group); geriatric teeth: SEM images of coronal third-heavy smear layer, score 2 middle third-moderate smear layer, score 2 apical third-moderate smear layer, score 2
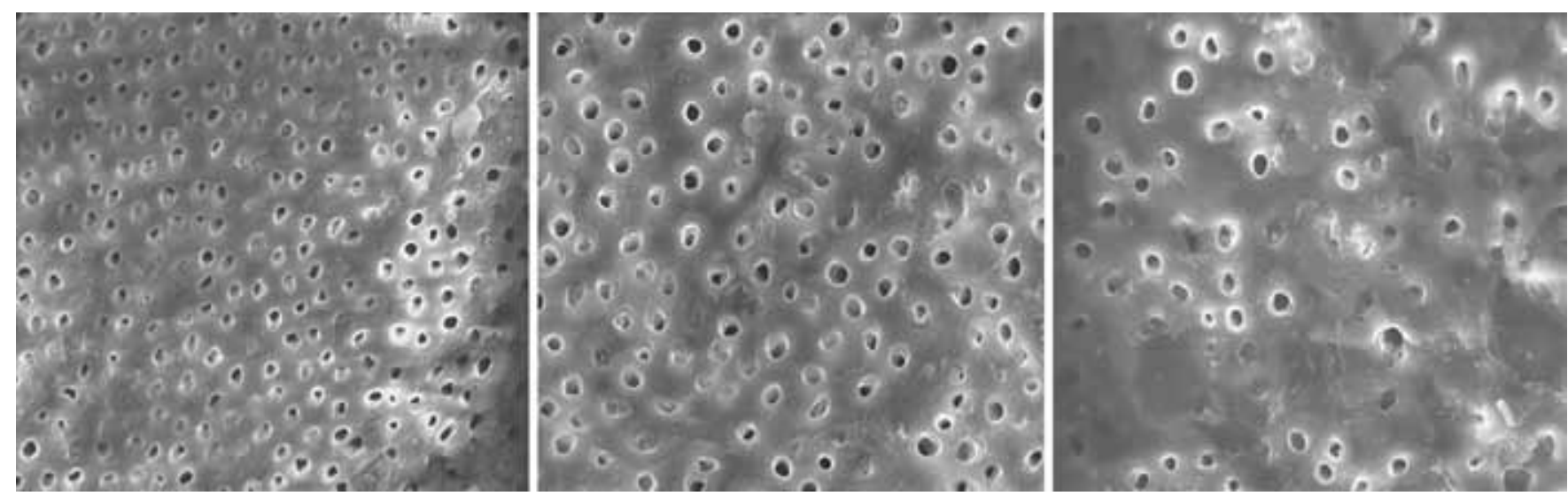

Fig. 6: Group 3B: PIPS group; geriatric teeth: SEM images of coronal third-no smear layer, score 0 middle third-no smear layer, score 0 apical third—no smear layer, score 0

0-no smear layer, no smear layer on the root canal surface, with all the tubules clean and open; 1 -moderate smear layer; 2-heavy smear layer, smear layer covers the root canal surface and the tubules.

\section{DISCUSSION}

In this study, teeth of three different age groups were used-the primary dentition, the adolescent dentition and the geriatric dentition. Many morphological changes take place in the dental pulp. Gradually, pulp becomes smaller through environmental effects and aging which have been concluded in several studies of dentin formation and calcifications. ${ }^{78}$ The different types of dentinprimary, secondary and tertiary dentin. ${ }^{9}$ However, the changes in the histological and physiological characteristics of dentin in relation to age is not thoroughly documented. Hence, the efficacy of smear layer removal in this study was compared between the pediatrics group, adolescent and geriatric groups. 
Whittaker and Kneale ${ }^{10}$ have studied mineralizing front at the dentin-predentin interface in human teeth. The younger teeth are almost or completely fused in terms of shape of calcospherites (ultimate fusion of many centers of calcification). Even in older teeth though the shape of calcospherites in the coronal part of the pulp cavity had a similar appearance to that of the younger teeth. In the mid-root and apical-root areas, the appearance of calcospherites was replaced with a less regular surface and fewer tubules.

The most commonly used irrigant in endodontics is sodium hypochlorite because it has bactericidal properties and causes tissue dissolution. ${ }^{11,12}$ Among other substances used for this purpose, EDTA has been superior in the removal of the smear layer in comparison with other substances in the final irrigation, ${ }^{13-17}$ justifying its use in the present study. In a study by Calt and Serper it was concluded that 10 minutes application of $10 \mathrm{ml}$ of 17\% EDTA caused excessive peritubular and intertubular dentinal erosion when compared with irrigation with for 1 minute which was effective in removal of smear layer. ${ }^{18-20}$ Baumgartner, Mader and Abbott et al observed an effective cleaning action on coronal, middle and apical thirds even when different quantities of solutions and times of irrigation were employed..$^{21,22}$ Results for the apical third agree with those of other studies done by Goldman et al, Barkhordar et al, O'Connell et al, Calt and Serper which showed that it is difficult to remove the smear layer in the apical region. ${ }^{23,24}$ Garberoglio and Becce, although noticed that the presence of smear plugs in some of the specimens, they reported that using EDTA for 30 seconds cleaned the apical third. ${ }^{25}$ In the present study, there was no smear layer appreciated in all the three levels, i.e. coronal, middle and apical third on using PIPS.

This study introduced several modifications to the commonly used laser-assisted techniques and protocols, to reduce the thermal effect of laser radiation on dentinal walls. FDA has approved Erbium:Yttrium-AluminumGarnet laser (Er:YAG, 2940 nanometer wavelength) for cleaning, shaping and enlarging of the root canal. Previous studies tested the ability and the effects of this laser on root canal walls and indicated that the Er:YAG laser is a suitable instrument for removal of the smear layer in root canals. ${ }^{26-32}$ Furthermore a 2008 paper, investigated the ability of both Er:YAG and Er,Cr:YSGG lasers equipped with conical shaped radially firing tips and plain tips, for removing smear layer from the apical third; the results showed a laser activation of EDTA and a better performance of conical fibers compared to plain fibers for improving the action of EDTAC in dissolving smear layer. ${ }^{33}$ In traditional irrigation protocols, syringe tip is placed closer to working length. Using this new laser system, the laser tip was not placed within the canals themselves. Tips are confined to the coronal chamber above the access opening which allows easy access for the photomechanical effects to occur within the root canal for cleaning of root canals.

The Er:YAG laser equipped with a novel 400 micron diameter radial and stripped tip using a subablative parameters of average power $0.3 \mathrm{~W}, 20 \mathrm{~mJ}$ at $15 \mathrm{~Hz}$ is proved to be effective at removing the smear layer. A possible explanation for this finding could be contributed when light energy is pulsed in liquid is seen with photomechanical effect. ${ }^{34-36}$ In fact, a profound 'shockwave-like' effect was observed when radial and striped tips were submerged in a root canal which is filled with liquid; due to very small volume this may remove the smear layer and decrease the bacterial load within the root canal system. ${ }^{37-39}$

We speculate that this phenomenon is responsible for the removal of smear layer in PIPS group, in which laser irradiation was combined with EDTA have an effect on smear layer removal. With the usage of lower subablative energy $(20 \mathrm{~mJ})$ and restricted placement of the tip to within the coronal portion of the orifice, the undesired effects of the thermal energy were avoided. ${ }^{27-32}$ The SEM images verified the efficient and minimally disruptive effects on the canal walls, dentinal tubules and even on the hydroxyapatite surfaces. No thermal damage was found in PIPS treated samples in the adolescent and the geriatric groups, whereas melting of the dentinal surface has been observed in the apical third of the pediatric group.

\section{CONCLUSION AND SUMMARY}

The findings of our studies on SEM analysis demonstrated that:

The efficacy of smear layer removal was better in the pediatrics group followed by adolescent and geriatric groups.

Within the study group, there was no smear layer appreciated in all the three levels, i.e. coronal, middle and apical third on using PIPS.

The PIPS technique resulted in effective debriding and decontamination of the root canal system.

\section{REFERENCES}

1. Haapasalo M, Endal U, Zandi H, Coil JM. Eradication of endodontic infection by instrumentation and irrigation solutions. Endodontic Topics 2005 March;10(1):77-102.

2. Olivi G, DiVito E. Photoacoustic endodontics using PIPSTм: experimental background and clinical protocol. J Laser Health Academy 2012, No. 1.

3. Myers TD. Lasers in dentistry. CDS Rev 1991 Sep;84(8):26-29.

4. Gutknecht N, Behrens VG. Instrumentation of root canal walls with Nd-YAG laser. Zahnarztl Welt Zahnarztl Rundsch 1991 Oct;100(10):748-750. 
5. DiVito E, Peters OA, Olivi G. Effectiveness of the Erbium:YAG laser and new design radial and stripped tips in removing the smear layer after root canal instrumentation. Lasers Medical Science; 2010 Dec 1.

6. DiVito E, Colonna M, Olivi G. The Photoacoustic efficacy of an Er: YAG Laser with radial and stripped tips on root canal dentin walls: an SEM evaluation. J Laser Dentist 2011;19(1): 156-161.

7. Philippas GG, Applebaum E. Age factor in secondary dentin formation. J Dent Res 1966;45(3):778-789.

8. Nitzan DW, Michaeli Y, Weinreb M, Azaz B. The effect of aging on tooth morphology: a study on impacted teeth. Oral Surg Oral Med Oral Pathol 1986;61(1):54-60.

9. Murray, et al. Age-related odontometric changes of human teeth. Oral Surgery Oral Medicine Oral Pathology 2002;93(4): 474-482.

10. Whittaker DK, Kneale MJ. The dentine-predentine interface in human teeth. A scanning electron microscope study. Br Dent J 1979 Jan 16;146(2):43-46.

11. Gutarts R, Nusstein J, Reader A, Beck M. In vivo debridement efficacy of ultrasonic irrigation following hand-rotary instrumentation in human mandibular molars. J Endodont 2005;31(3):166.

12. Sirtes G, Waltimo T, Schaetzle M, Zehnder M. The effects of temperature on sodium hypochlorite short-term stability, pulp dissolution capacity and antimicrobial efficacy. J Endodont 2005;31(9):669-671.

13. Vasconcelos BC, Luna-Cruz SM, De-Deus G, Moraes IG, Maniglia-Ferreira C, Gurgel-Filho ED. Cleaning ability of chlorhexidine gel and sodium hypochlorite associated or not with EDTA as root canal irrigants: scanning electron microscopy study. J Applied Oral Sci 2007;15(5):387-391.

14. Carvalho AS, et al. Smear layer removal by auxiliary chemical substances in biomechanical preparation: a scanning electron microscope study. J Endodontol 2008;34(11): 1396-1400.

15. Lui JN, Kuah HG, Chen NN. Effect of EDTA with and without surfactants or ultrasonics on removal of smear layer. J Endodont 2007;33(4):472-475.

16. Chopra S, Murray PE, Namerow KN. A scanning electron microscopic evaluation of the effectiveness of the f-file versus ultrasonic activation of a K-file to remove smear layer. J Endodont 2008;34(10):1243-1245.

17. Mello I, Robazza CRC, Antoniazzi JH, Coil J. Influence of different volumes of EDTA for final rinse on smear layer removal. Oral Surg Oral Med Oral Pathol Oral Radiol 2008; 106:e40.

18. Yazdizadeh M, Feizianfard M. Determination of the minimum instrumentation size for penetration of irrigants to the apical third of root canal systems. J Endodont 2006;32(5): 417-420.

19. Calt S. Serper smear layer removal by EGTA. J Endodont 2000;26(8):459-461.

20. Calt $S$, Serper A. Time-dependent effects of EDTA on dentin structures. J Endodont 2002;28(1):17-19.

21. Baumgartner JC, Cuenin PR. Efficacy of several concentrations of sodium hypochlorite for root canal irrigation. J Endodont 1992;18(12):605-612.

22. Baumgartner JC, Mader CL. A scanning electron microscopic evaluation of four root canal irrigation regimens. J Endodont 1987;13(4):147-157.
23. Goldman LB, Cavaleri R, Bogis J, Lin PS. The efficacy of several endodontic irrigating solutions: a scanning electron microscopic study: part 2. J Endodont 1982;8(11):487-492.

24. Barkhordar RA, Watanabe LG, Marshall GW, Hussain MZ. Removal of intracanal smear by doxycycline in vitro. Oral Surg Oral Med Oral Pathol 1997;84(4):420-423.

25. Garberoglio R, Becce C. Smear layer removal by root canal irrigants: a comparative scanning electron microscopic study. Oral Surg Oral Med Oral Pathol 1994;78(3):359-367.

26. Sulewski JG. Making the most of the 16th annual conference and exhibition: A practical orientation for attendees, April 22, 2009:6-21. Academy of Laser Dentistry 16th Annual Conference and Exhibition, Las Vegas, Nevada; 2009 April 22-26.

27. Takeda FH, Harashima T, Kimura Y, Matsumoto K. Comparative study about the removal of smear layer by three types of laser devices. J Clinical Laser Med Surg 1998;16(2):117-122.

28. Matsuoka E, Kimura Y, Matsumoto K. Studies on the removal of debris near the apical seats by Er: YAG laser and assessment with a fiberscope. J Clin Laser Med Surg 1998;16(5):255-261.

29. Takeda FH,Harashima T, Eto JN, Kimura Y, Matsumoto K. Effect of Er:YAG laser treatment on the root canal walls of human teeth: an SEM study. Endodont Dent Traumatol 1998;14(6):270-273.

30. Takeda FH, Harashima T, Kimura Y, Matsumoto K. Efficacy of Er: YAG laser irradiation in removing debris and smear layer on root canal walls. J Endodontics 1998;24(8):548-551.

31. Takeda FH, et al. A comparative study of the removal of smear layer by three endodontic irrigants and two types of laser. Int Endodont J 1998;32(1):32-39.

32. Pecora JD, et al. Evaluation of dentin root canal permeability after instrumentation and Er:YAG laser application. Lasers Surg Med 2000;26(3):277-281.

33. George R, Meyers IA, Walsh LJ. Laser activation of endodontic irrigants with improved conical laser fiber tips for removing smear layer in the apical third of the root canal. J Endodont 2008;34(12):1524-1527.

34. Blanken J, et al. Laser induced explosive vapor and cavitation resulting in effective irrigation of the root canal. Part 1 : a visualization study. Lasers in Surg Med 2009 Sep;41(7): 514-519.

35. De Moor RJ, et al. Laser induced explosive vapor and cavitation resulting in effective irrigation of the root canal. Part 2: evaluation of the efficacy. Lasers in Surg Med 2009 Sep; 41(7):520-523.

36. de Groot SD, et al. Laser activated irrigation within root canals: cleaning efficacy and flow visualization. Int Endodont J 2009 Dec;42(12):1077-1083.

37. Schoop U, et al. The use of the erbium, chromium: yttriumscandium-gallium-garnet laser in endodontic treatment: the results of an in vitro study. J Am Dent Associat 2007;138:949-955.

38. Schoop U, et al. The impact of an erbium, chromium:yttriumscandium-gallium-garnet laser with radial-firing tips on endodontic treatment. Lasers in Med Sci 2009;24(1):59-65.

39. Gordon $\mathrm{W}$, et al. The antimicrobial efficacy of the erbium, chromium: yttrium-scandium-gallium-garnet laser with radial emitting tips on root canal dentin walls infected with enterococcus faecalis. J Am Dent Assoc 2007 Jul;138(7):992-1002. 